\title{
Demographic Characteristics as Determinants of the Use of Health Care Services: A Case of Nsukka, Southeast Nigeria
}

\author{
Beatrice D. Adeoye \\ Department of Sociology, Federal University, Oye-Ekiti, Nigeria \\ Email: beatrice.adeoye@fuoye.edu.ng \\ Received 11 September 2015; accepted 4 December 2015; published 7 December 2015 \\ Copyright (C) 2015 by author and Scientific Research Publishing Inc. \\ This work is licensed under the Creative Commons Attribution International License (CC BY). \\ http://creativecommons.org/licenses/by/4.0/

(c) (i) Open Access

\begin{abstract}
Studies have associated demographic characteristics as strong determinants of utilization of health care services; however, not much has been done to explore the dynamics of these variables in Nigeria. This empirical study explores the link between demographic factors and the use of health care services. 543 respondents were selected using multi-stage sampling technique. The findings showed that a majority $(56.9 \%)$ of the respondents were female while $(50.3 \%)$ were married. Testing the demographic characteristics regarding where people will prefer to go for treatment with multiple regression, it is only sex as a demographic variable that indicates positive association, with 0.08 level of significance. Variables such as age and education did not indicate any strong correlation with health care services utilization in the study area. This result corroborates the reality in many parts of African society where it is the father that dictates the cause of action. That means gender plays an important role in the utilization of health care delivery.
\end{abstract}

\section{Keywords}

Demographic Characters, Determinant, Health Care, Treatment, Self-Medication, Symptom

\section{Introduction}

According to Erinosho (2006) [1], social status is intrinsically linked to health. Highly educated Nigerians are less likely to think that various physical disorders are caused by witchcraft, but may do so if illness is of an emotional or intractable nature. Furthermore, the highly educated people are not susceptible to preventable disease 
partly because of their personal hygiene.

Benyoussef (1977) [2] in his research on the factors that determine high and low level of utilization of health services discovers that there are cultural and economic differences existing between the categories of those that make use of health services and those that do not. He asserts that the effect of socio-economic status as a factor influencing choice and utilization of health facilities is more pronounced in developing countries because of the greater relative differences, and also because of the scarcity of health services. In addition, it is often argued that there is an interdependent relationship between health and social problems, but to what extent is the relationship? Popple (2002) [3] says health picture of the nation is thus complex and fluid. Costs are rising and they are covered by funds from diverse sources. Many health indicators have improved yet. These improvements vary according to social class, age and gender. Blaxter (1990) [4] found out that poorer families seemed more likely to place greater stress on health and illness in terms of the disruption of their lives and an ability to "accommodate" minor illnesses, while still "getting on" with their lives. According to Belling and ceiger (1972) [5], the well educated people usually in the upper income group, tend to have more knowledge of disease and are more sensitivity to symptoms. The influence of ethnicity upon health care utilization is large due to the shared framework within which ethic group view the provision of health services. Also age has been found to lack significance in explaining the relationship between income and physician visit. Finally in the case of health care utilization, role of the social network and its specific values, opinions, attitude, and cultural background act to suggest, advice or coerce an individual into taking or not taking a particular course of action regarding health care. Conformity with the social network's recommendation could reduce a person's anxiety by ensuring the approval of significant others. Mckinlay and Arches (1985) [6] found, for example, that persons with close-knit and interlocking social networks tended to display greater conformity with these reference groups than those with loose-knit differential social network

Finally, studies over the years reveal that non-utilization of heath care services is higher in rural areas than in urban areas. Levels of education, caste, affordability (asset-holding) and culture were factors which determined the utilization pattern. The lowest socio-economic class had the highest non-utilisation rate and the highest public sector utilization rate (Jeckins, 1987) [7]. Igun (1996) [8] is of the view that inadequate utilization of health facilities is as a result of social and environmental factors. There is an absolute shortage and the situation is often complicated by the distribution of health resources that exist. Also non utilization of health facilities could relatively reflect such factors as attitude of health personnel, insufficient awareness of the need for community knowledge and involvement and social inaccessibility. This study examined the links between demographic factors and the use of health care services in Nsukka, Southeast, Nigeria. Also to ascertain who determines where and when to use health care services in the families.

\section{Theoretical Frame Work}

This study draws its theoretical framework from Health Belief Model of Irwin Rosenstock (1966) [9] and his colleague Becker (1977) [10].

One of the most influential social-psychological approaches designed to account for the ways in which healthy people seek to avoid illness is Health Belief Model of Irwin Rosenstock (1966) [9] and his colleague Becker (1977) [10]. The Health Belief Model is derived from a great extent from the theories of Kurt Lewin and other psychologists who believe that people exist in a life space composed of regions with both positive and negative valences (values). An illness would have a negative valence and would have the effect of pushing a person away from that region, unless doing so would cause the person to enter a region of even greater negative region valence. While people are pushed away from regions within negative valences, they are attracted towards regions of positive valences. Thus, a person's behaviour might be viewed as the result of seeking region which offers the most attractive values. According to this model, human behaviour is seen as being dependent upon two primary variables 1 ) the values placed by a person upon a particular outcome and 2) the person's belief that a given action will result in that outcome.

According to Kirschy (1974) [11] Health Belief Model demonstrated considerable utility in the study of health behaviour and may yet be modified to account for illness behaviour as well. The merit of this model is that, even when an individual recognizes personal susceptibility he/she may not take action unless the individual also perceives that being ill will result into serious difficulty. Thus, the individual's subjective assessment of the health situation becomes the critical variable in the utilization of health services. In fact, a person's subjective 
assessment may be more important than an objective medical diagnosis (Barbara, 1997) [12].

\section{Methodology}

The exploratory study used both qualitative and quantitative research methods. The study area was Nsukka town in Nsukka Local Government Area of Enugu state, Southeast Nigeria. Nsukka town is divided into three autonomous communities. Nsukka is characterized by some social-cultural practices like: Masquerading, male child preferences, belief in food taboos such as forbidding women and child from eating food etc. the population for this study is 48,177 which consist of people who are 15 years and above which assumed that people within this age range would have being use to medication and health related issues. Using 50 percent of population and confidence interval of 95\% within 2.5 percentage error margin, sample size of 602 was calculated. However, to allow even distribution between the 3 autonomous communities that make up Nsukka town, the calculated sample size was approximated to 600 persons who are 15 years and above. Multi-stage random sampling technique and purposive method was used in this study. Among the 3 autonomous communities in Nsukka town, 4 villages were selected in each autonomous using simple random sampling (balloting) technique. This gave total number of 12 villages. In each of the villages 10 household were selected each using purposive technique. This gave total number of 120 household. 5 respondents were selected in each of the selected household using availability sampling method. This made the total number of the respondents to be 600 respondents. For qualitative data. Two in-depth interviews were conducted. The two in-depth interviews was for health care provider and community leaders in the study areas. One major hospital were selected in each of the 3 autonomous communities which made up 3 hospitals, in which 4 health providers were interviewed in each hospital. This will give total number or 12 health providers. In each of the 12 villages selected one community leader was interviewed. On the whole 24 respondents were interviewed using in-depth interview guide. Two instruments were used for the study these were questionnaire and in-depth interview guide The analysis was done using Statistical Package for Social Science (SPSS). This was used for quantitative data while qualitative data were analyzed using thematic method.

\section{Findings}

Majority (56.9\%) of the respondents were female while $43.1 \%$ are male. More of the respondents were married (50.3\%), single (34.6\%), divorce and separated are 5.0\% and 2.0\% respectively. Widows were $4.2 \%$ while widowers were $4.2 \%$. People within age 16 - 35 were of majority (41.3\%), followed by 15 - 25 age range (23.9\%), others between 36 - 65 were very few.

Farmers constituted $19.2 \%$ of the sample. Other occupation groupings constituted varying proportions of sample. Notable among the other occupational groupings in the sample were people that were into business (17.2\%), petty traders (16.8\%), school teachers (10.9\%), civil servant (17.3\%), unemployed (8.8\%). Others (9.9\%) were students.

Majority (36.1\%) of the respondents had secondary school education 14.5\% had NCE/OND education. 20.1\% had first school leaving certificate (FSLC), 11.4\% had degree, 6.4\% had higher degree while $11.2 \%$ had no formal education (Table 1 ).

Majority (47.1\%) of people within age 15 - 25, said their parents decides where and when to go for treatment. Majority (58.9\%) within age 26 - 35, said their spouse decides for them. Majority (10.8\%) of people that fall within age 46 - 55 take the decision themselves, while majority (15.2\%) and (21.2\%) of people within age 55 65 and 65 and above respectively, indicated that their relatives decide for them.

Hypothesis states that people with higher educational qualification tends to make use of hospital/clinic more than people with lower educational qualification. In the study, people that FSLC and “O” level certificate are grouped under low educational level while those that have NCE/OND, B.Sc. and Higher degree are grouped under high educational level. This hypothesis was tested using chi-square (Table 2).

Majority (67.6\%) of people that prefer hospital for treatment are people with high educational qualification. But based on chi-square result there is no statistical relationship between education qualification and the use of modern medicine (Table 3 ).

Result show there is no statistical relationship between educational level and opinion about modern drugs.

reveals that the majority (81.4\%) indicate that people with high income and education patronize hospital mostly. Some $12.2 \%$ disagree, it is not so, while very few (6.5\%) respondents indicate that they are not sure. 
Table 1. Distribution of respondents by socio-demographic characteristics and nsukka autonomous communities $(\mathrm{N}=543)$.

\begin{tabular}{|c|c|c|c|c|}
\hline \multicolumn{5}{|c|}{ Nsukka Autonomous Communities } \\
\hline Characteristics & Nru Nsukka (\%) & Ihe/Owerri (\%) & Nkpunano (\%) & Total (\%) \\
\hline \multicolumn{5}{|l|}{ Sex } \\
\hline Male & 69 (37.5) & 71 (39.9) & $94(17.3)$ & 234 (43.1) \\
\hline Female & $115(62.5)$ & $107(60.1)$ & $87(16.0)$ & 309 (56.9) \\
\hline \multicolumn{5}{|l|}{ Age } \\
\hline $15-25$ & 36 (19.6) & $49(27.5)$ & 45 (24.9) & 130 (23.9) \\
\hline $26-35$ & $63(34.2)$ & $86(48.3)$ & 78 (43.1) & 227 (41.8) \\
\hline $36-45$ & $41(22.3)$ & 24 (13.5) & $29(16.0)$ & 94 (17.3) \\
\hline $46-55$ & $20(10.9)$ & $10(5.6)$ & $14(7.7)$ & $44(8.2)$ \\
\hline $56-65$ & $14(7.6)$ & $8(4.5)$ & $13(7.2)$ & $35(6.4)$ \\
\hline 66- and above & $10(5.4)$ & $1(6)$ & $2(1.1)$ & $13(2.4)$ \\
\hline \multicolumn{5}{|l|}{ Marital Status } \\
\hline Married & $117(63.3)$ & $67(37.6)$ & $89(49.2)$ & $273(50.3)$ \\
\hline Single & 49 (26.6) & $71(39.9)$ & 68 (37.6) & $188(34.6)$ \\
\hline Divorce & $3(1.6)$ & 19 (10.7) & $5(2.8)$ & $27(5.0)$ \\
\hline Separated & $2(1.1)$ & $8(4.5)$ & $5(1.1)$ & $12(2.2)$ \\
\hline Widow & $10(5.4)$ & $8(4.5)$ & $5(2.8)$ & $23(4.2)$ \\
\hline Widower & $3(1.6)$ & $5(6.6)$ & $12(6.6)$ & $20(3.7)$ \\
\hline \multicolumn{5}{|l|}{ Education } \\
\hline No formal Education & $20(10.9)$ & $24(13.5)$ & $17(9.4)$ & $61(11.2)$ \\
\hline FSLC & 55 (29.9) & $20(11.2)$ & 34 (18.8) & $109(20.11)$ \\
\hline SSCE & 57 (31.1) & 75 (42.1) & 65 (35.9) & $197(36.3)$ \\
\hline NCE/OND & $28(15.2)$ & $22(12.4)$ & $29(16.0)$ & $79(14.5)$ \\
\hline BSC & $10(5.4)$ & 27 (15.2) & $25(13.8)$ & $62(11.4)$ \\
\hline Higher Degree & $14(7.6)$ & $10(5.6)$ & $11(6.1)$ & $35(6.4)$ \\
\hline \multicolumn{5}{|l|}{ Religion } \\
\hline Christian & 112 (88.6) & $141(79.2)$ & $152(84.0)$ & 455 (83.8) \\
\hline Islam & $1(0.5)$ & $6(3.4)$ & $14(7.7)$ & 21 (3.9) \\
\hline Traditional & $21(3.9)$ & $31(5.7)$ & $15(8.3)$ & $67(12.3)$ \\
\hline \multicolumn{5}{|l|}{ Occupation } \\
\hline Farming & $46(25.0)$ & $23(12.9)$ & $37(20.4)$ & $106(19.5)$ \\
\hline Petty Trading & $34(18.5)$ & $20(11.2)$ & $33(18.2)$ & $87(16.0)$ \\
\hline Business & 35 (19.0) & $42(23.6)$ & $26(14.4)$ & $103(19.0)$ \\
\hline School Teacher & 14 (26.9) & $13(7.3)$ & 25 (13.8) & $52(9.6)$ \\
\hline Civil Servant & $37(20.1)$ & $30(16.9)$ & $26(14.4)$ & $93(17.1)$ \\
\hline Unemployed & $3(1.6)$ & $22(12.4)$ & $23(12.7)$ & $48(8.8)$ \\
\hline Student & $15(8.2)$ & 28 (15.7) & $11(6.1)$ & 54 (9.9) \\
\hline
\end{tabular}

Table 2. Distribution of respondents by age and who determines where and when to go for treatment $(\mathrm{N}=543)$.

\begin{tabular}{|c|c|c|c|c|c|}
\hline \multicolumn{6}{|c|}{ Who Determines Place of Treatment } \\
\hline Age in Years & Your Spouse & Parents & Your Relation & Yourself & Total \\
\hline $15-25$ & $11(15.1)$ & $57(47.1)$ & $5(15.2)$ & $57(18.0)$ & $130(23.7)$ \\
\hline $26-35$ & $43(58.9)$ & $45(37.2)$ & $11(33.3)$ & $128(40.5)$ & $227(41.8)$ \\
\hline $36-45$ & $15(20.5)$ & $12(9.9)$ & $5(15.2)$ & $62(19.6)$ & 94 (17.3) \\
\hline $46-55$ & $3(4.1)$ & $7(5.8)$ & $0(0)$ & $34(10.8)$ & $44(8.1)$ \\
\hline $55-65$ & $1(1.4)$ & $0(0)$ & $5(15.2)$ & $29(9.2)$ & $35(6.4)$ \\
\hline 65 above & $0(0)$ & $0(0)$ & $7(21.2)$ & $6(1.9)$ & $13(2.4)$ \\
\hline
\end{tabular}


Hypothesis states that there is a relationship between knowledge and response to health services. This hypothesis was tested using chi-square (Table 4).

Table reveals the regression that measure level of occurrence of where people prefer to go first for treatment. It is only Sex that indicates positive association for future occurrence to where people will prefer to go first for treatment with 0.08 significance. Age and education indicates no association considering their level of significant. This result shows that sex is one of the determinant factors of where and when people will go for treatment. This is pointing out the ideal condition of our society where in the family setting, it is the father that dictates the cause of action. Also to buttress this findings in this study table seven revealed that majority (58.9\%) within age 26 - 35 said is their spouses that decide on where and when to go for treatment. This can also be trace to the issues of finance since it is the head of the family (father) that always handle financial responsibilities in the home.

According to one of the community leaders in an in-depth interview said "it is the sponsor or financier that decide on where and when to go for treatment" (community leader, male, age 68). This shows that sex can be taken as one of the main factors that determine the response or attitude of people to health care services (Table $5)$.

\section{Conclusion}

The result shows gender as a strong determinant factor or a significant predictor as regards health care utilization and administration. Thus this paper recommends that to improve on the level of healthservice utilization, demographic characteristics should be given adequate consideration. This is particularly germane for most parts of

Table 3. Educational qualification and preferred place for treatment.

\begin{tabular}{cccccc}
\hline $\begin{array}{c}\text { Level of } \\
\text { Education }\end{array}$ & Hospital & $\begin{array}{c}\text { Traditional } \\
\text { Healer }\end{array}$ & Prayer Houses & Medicine Stores & Self Medication \\
\hline Low Education & $1(33.3)$ & $33(57.9)$ & $138(68.0)$ & $157(69.2)$ & $38(71.7)$ \\
$\begin{array}{c}\text { Higher } \\
\text { Education }\end{array}$ & $2(66.7)$ & $24(42.1)$ & $65(32.0)$ & $70(30.8)$ & $15(28.3)$ \\
\hline
\end{tabular}

$\mathrm{X}^{2}(1, \mathrm{~N}=543)=4.732 \mathrm{P}<0.316$

Table 4. Educational qualification and opinion to modern drug.

\begin{tabular}{cccc}
\hline Educational Level & Effective & Not Effective & Total \\
\hline High Education & $117(34.0)$ & $59(29.6)$ & $176(32.4)$ \\
Low Education & $227(66.0)$ & $140(70.4)$ & $367(67.6)$ \\
\hline
\end{tabular}

$\mathrm{X}^{2}(1, \mathrm{~N}=543)=1.096 \mathrm{P}<0.294$

Table 5. Regression analysis of the place people preferred to go first for treatment with related characteristic. variables in the equation.

\begin{tabular}{|c|c|c|c|c|c|c|}
\hline & B & S.E & Wald & df & Sig & $\operatorname{Exp}(\mathrm{B})$ \\
\hline Education & $=198$ & 0.194 & 1.041 & 1 & 0.307 & 0.821 \\
\hline New age & 0.073 & 0.238 & 0.094 & 1 & 0.759 & 1.076 \\
\hline Sex & -312 & 0.179 & 3.025 & 1 & 0.082 & 0.732 \\
\hline Constant & 0.104 & 0.479 & 0.047 & 1 & 0.829 & 1.109 \\
\hline
\end{tabular}


African society where patriarchal family system is relatively more predominant.

\section{References}

[1] Erinosho, O.A. (2006) Health Sociology. Budwant Consult, Ijebu-Ode.

[2] Benyoussef, A. (1977) Health services in Developing Countries International Journal of Social Sciences, 30, 397-403.

[3] Popple, D. (2002) Health Care: Direct Practices. Encyclopedia of Social Work. NASW Inc., Washington DC.

[4] Blaxter, M. (1990) Health and Lifestyles. Routledge, London. http://dx.doi.org/10.4324/9780203393000

[5] Bellin, S.S. and Geiger, H.J. (1972) The Impact of a Neighborhood health centre on a patient's Behaviour and Attitudes Relating to Health Care: A Study of a Low Income Housing Project. Medical Care, 10, 224-239.

[6] Mckinlay, J. and Arches, J. (1985) Towards Protetarianization of Physicians. International Journals of Health Science, 15, 161-195.

[7] Jeckins, C.D. (1987) Overview: Behavioral Perspective on Health Risks and Social Disadvantages. Academy Press, Washington DC.

[8] Igun, U.A. (1988) Medical Sociology: An Introduction. Shaneson C. I. Press, Ibadan.

[9] Rosestock, I. (1966) Why People Use Health Services. Milkbank Memorial Fund Quarterly, 44, 94-127. http://dx.doi.org/10.2307/3348967

[10] Becker, M.H. (1977) Selected Psychological Models and Correlates of Individual Health-Related Behaviour. Medical care, 15, 27-46. http://dx.doi.org/10.1097/00005650-197705001-00005

[11] Kirschy, J. (1974) Illness Behaviour in the Health Belief Model. Personal Health Journal, 387-408.

[12] Barbara, B. (1997) The Emerging Health Care Word: Implication for Social Work Practice and Education. Social Work, 41, 541-551. 